\title{
Simple mathematical model to predict the amount of energy produced in wind turbine - preliminary study
}

\author{
Sylwester Borowski ${ }^{1,}{ }^{*}$, Agnieszka Sołtysiak ${ }^{1}$, Klaudiusz M igawa ${ }^{1}$ and Andrzej Neubauer \\ ${ }^{1}$ UTP University of Science and Technology, Faculty of Mechanical Engineering, Al. prof. S. \\ Kaliskiego 7, 85-796 Bydgoszcz, Poland
}

\begin{abstract}
The manuscript presents a simple mathematical model for predicting the amount of energy produced in a wind turbine. As part of the own research, the data obtained from the SCA DA program for the Enercon E-82 wind turbine was analyzed. It has been shown that it is possible to build a mathematical model to determine the amount of energy produced from the average wind speed. This method will be primarily useful for forecasting the volume of production as well as el ectricity demand, with particular emphasis on renewable energy sources. The application of the developed method in practice will facilitate and accelerate the implementation of the decisionmaking process in electricity production systems, while reducing the risk of error. This model can also be used to make repowering decisions.
\end{abstract}

\section{Introduction}

The high share of wind energy in the national power system creates many problems. They are caused by unstable operation of wind farms due to changing wind speed. During normal use, there are also periods without electricity production. Due to the planned demand for electricity in the energy system, such a situation is unfavorable. A constant production of electricity must be maintained in the energy system. It must correspond to the demand. In the case of high variability of electricity production, it is necessary to maintain other sources. An "energy mix" is being created based on electricity from renewable sources and fossil fuels. Energy storage facilities based on hydropower plants and accumulators are also maintained. A system constructed in this way must ensure a high potential for reliability of electricity supply. Maintaining such a complex system incurs high costs. They are related to construction and maintenance $[1,2]$.

Wind farm repowering is the process of replacing existing wind turbines with new turbines. New turbines are of higher rated power or higher efficiency. Such a reconstruction results in an increase in net electricity generated.

The use of wind energy has grown significantly in the world in recent times. The wind energy technology offered today has improved significantly. This is due to the increase in the size of the wind turbines. The process of forecasting and modeling wind resources is also improved. Better knowledge of the behavior of the wind results in an optimal wind farm design. Electricity generation costs have been reduced [3]. Wind power plants in the best locations are competitive with respect to conventional power generation technology.

Due to technological changes, there is a process of technological aging of wind turbines. At the same time, difficulties in finding new sites for the construction of wind turbines are visible. This situation causes interest in repowering. It is the process of replacing existing wind turbines with new turbines with higher rated power or greater efficiency. Replacing an old turbine with a new generation turbine results in an increase in net energy production. The

* Corresponding author: sylwester.borowski@ utp.edu.pl 
repowering process also includes the modernization of the installation with an increase in power and efficiency [4].

However, making decisions requires conducting analyzes that will clearly indicate the legitimacy of the change [5]. The process of making decisions about repowering depends to a large extent on identifying potential benefits. One of the premises may be the estimation of the difference between the amount of energy produced by the current turbine and the newly planned one. Having a mathematical model of energy production by a new turbine makes it possible to indicate the benefits for the investor.

The physical wear of the turbine is also important for the repowering process. During the use of the wind turbine, the coatings of the turbine blades are destroyed and the resistance increases. These resistances change the power curve for the turbine. It is also possible to use the resulting models to analyze the wear of the turbine blades. Blade failure can also increase harmful noise and vibration levels $[6,7,8,9]$.

The aim of the manuscript is to present preliminary analytical research on the construction of a simple mathematical model that allows for the prediction of electricity production depending on the average wind strength. The model is built on the basis of historical data obtained from the Enercon SCADA program [10].

\section{Methodology}

The object of the analysis was the Wicko wind farm. It consists of five Enercon E-82 wind turbines. As part of the research, historical data was obtained and subjected to statistical analysis. The main goal of the research was to develop regression models. These models are to enable the determination of average daily amounts of electricity produced by wind turbines depending on the average daily wind speed. The designated models are based on historical values obtained from the SCADA system. Therefore, they are suitable for the analyzed wind turbine. This is due to the lack of analysis of other factors that may depend on the location of the wind turbine. Such factors include the roughness of the terrain, daytime temperature and other disturbing factors $[11,12,13]$.

As part of the analyzes, two linear regression models were developed. In the first case, the influence of the average daily wind speed on the amount of energy produced during the month was analyzed. The analysis was carried out for the entire year 2019. For the second model, the impact of the average daily wind speed on the amount of energy produced during the week was analyzed. The analysis was carried out for the entire year 2019 .

The designated regression models were developed on the basis of operational data obtained from the Enercon SCADA system. The actual data obtained concerned the average daily wind speed $\left[\mathrm{m} \mathrm{s}^{-1}\right]$ and the average daily electricity production $[\mathrm{kWh}]$ in the considered time period. The wind speed is obtained from a meter located on the nacelle of the wind turbine.

\section{Analysis of the results}

\subsection{Linear regression model developed for individual months of 2019}

The analysis was based on data obtained from the Enercon SCADA system. Table 3 shows the actual data for the considered wind turbine. For the construction of the model for individual months, the data was based on Average daily energy - column 2, Average daily wind speed - column 1. On their basis, a linear regression model was developed. It determines the dependence of the average daily amount of electricity produced on the average daily wind speed.

Formula (1) shows the linear regression function developed for individual months of 2019. Tables 1 and 2 present the statistics of the developed regression model.

$$
E_{\mathrm{m}}=4398.12 v_{\mathrm{m}}-14404.94
$$


where:

$\mathrm{E}_{\mathrm{m}}$ - average daily energy $[\mathrm{kWh}]$,

$\mathrm{V}_{\mathrm{m}}$ - average daily wind speed $\left[\mathrm{m} \mathrm{s}^{-1}\right]$.

Table 1. Statistics of the linear regression model developed for individual months of 2019.

\begin{tabular}{|c|c|}
\hline Coefficient & Value of the coefficient \\
\hline Correlation coefficient $\mathrm{R}$ & 0.9938 \\
\hline $\mathrm{R}^{2}$ & 0.9875 \\
\hline Adjusted $\mathrm{R}^{2}$ & 0.9863 \\
\hline Standard error & 379.5719 \\
\hline Number of observations & 12 \\
\hline
\end{tabular}

Table 2. Results of the statistical analysis of the coefficients of the linear regression function developed for individual months of 2019.

\begin{tabular}{|c|c|c|c|c|c|c|}
\hline Coefficient & $\begin{array}{c}\text { Value of the } \\
\text { coefficient }\end{array}$ & $\begin{array}{c}\text { Standard } \\
\text { error }\end{array}$ & t Stat & p- Value & Lower 95\% & Upper 95\% \\
\hline a & 4398.12 & 156.16 & 28.16 & $7.39892 \mathrm{E}-11$ & 4050.17 & 4746.06 \\
\hline b & -14404.94 & 922.31 & -15.62 & $2.37016 \mathrm{E}-08$ & -16459.98 & -12349.89 \\
\hline
\end{tabular}

Then, for the linear regression model represented by the formula (1), the values of the average daily amount of electricity produced were determined depending on the average daily wind speed. The obtained results are presented in Table 3, column 4 (Average daily energy Regression model) and in Figure 1.

Table 3. Average daily energy [kWh] generated by the Wicko wind farm in the following months of 2019 determined on the basis of real data (Enercon SCADA) and for the linear regression model.

\begin{tabular}{|c|c|c|c|}
\hline Month & $\begin{array}{c}\text { Average daily wind } \\
\left.\text { speed [m s } \mathbf{~ s}^{-1}\right] \\
\text { Enercon SCADA }\end{array}$ & $\begin{array}{c}\text { Average daily energy } \\
{[\mathbf{k W h} \text { ] }} \\
\text { Enercon SCADA }\end{array}$ & $\begin{array}{c}\text { Average daily energy } \\
{[\mathbf{k W h}]} \\
\text { Regression model }\end{array}$ \\
\hline 1 & 6.16 & 11894.92 & 12680.13 \\
\hline 2 & 6.46 & 13855.39 & 13994.33 \\
\hline 3 & 7.19 & 17246.77 & 17233.13 \\
\hline 4 & 5.77 & 11526.37 & 10972.20 \\
\hline 5 & 5.71 & 10540.13 & 10692.71 \\
\hline 6 & 5.05 & 7899.03 & 7820.21 \\
\hline 7 & 5.47 & 9850.87 & 9657.02 \\
\hline 8 & 4.57 & 5740.19 & 5698.71 \\
\hline 9 & 6.36 & 13665.17 & 13567.09 \\
\hline 10 & 5.38 & 9299.77 & 9245.58 \\
\hline 11 & 5.60 & 9775.40 & 10209.86 \\
\hline 12 & 6.66 & 15354.97 & 14878.01 \\
\hline
\end{tabular}




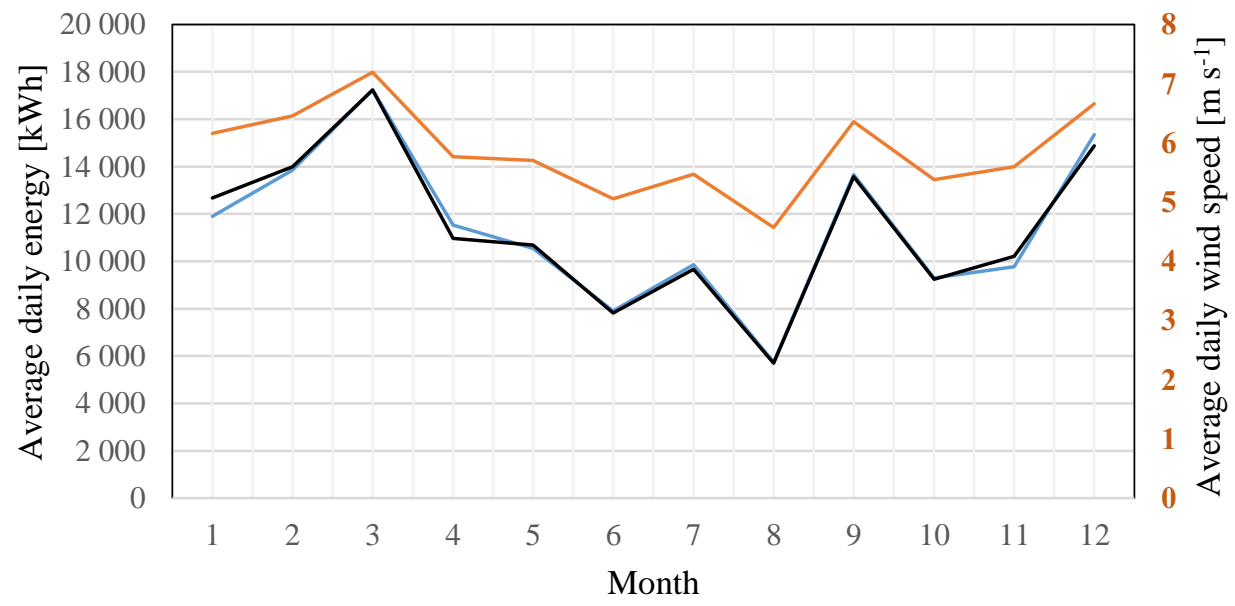

—Energy - Enercon SCADA ——Energy - Regression model — W W ind speed

Fig. 1. Average monthly energy $[\mathrm{kWh}]$ generated by the Wicko wind farm in the following months of 2019 determined on the basis of real data (Enercon SCADA) and for the linear regression model.

\subsection{Linear regression model developed for each week of 2019}

The weekly analysis was based on the data obtained from the Enercon SCADA system. Table 6 shows the actual data for the considered wind turbine. For the construction of the model for individual months, the data was based on Average daily energy - column 2, Average daily wind speed - column 1 . On their basis, a linear regression model was developed. It determines the dependence of the average daily amount of electricity produced on the average daily wind speed.

Formula (2) presents the linear regression function developed for individual weeks of 2019. Tables 4 and 5 present the statistics of the developed regression model.

where:

$$
E_{\mathrm{m}=5022.27 v_{\mathrm{m}}-17960.18}
$$

$E_{m}$ - average daily energy [kWh],

$\mathrm{V}_{\mathrm{m}}$ - average daily wind speed $\left[\mathrm{m} \mathrm{s}^{-1}\right]$.

Table 4. Statistics of the linear regression model developed for individual weeks of 2019.

\begin{tabular}{|c|c|}
\hline Coefficient & Value of the coefficient \\
\hline Correlation coefficient $\mathrm{R}$ & 0.9832 \\
\hline $\mathrm{R}^{2}$ & 0.9667 \\
\hline Adjusted $\mathrm{R}^{2}$ & 0.9660 \\
\hline Standard error & 1255.5474 \\
\hline Number of observations & 52 \\
\hline
\end{tabular}


Table 5. Results of the statistical analysis of the coefficients of the linear regression function developed for individual weeks of 2019.

\begin{tabular}{|c|c|c|c|c|c|c|}
\hline Coefficient & $\begin{array}{c}\text { Value of the } \\
\text { coefficient }\end{array}$ & $\begin{array}{c}\text { Standard } \\
\text { error }\end{array}$ & t Stat & p- Value & Lower 95\% & Upper 95\% \\
\hline a & 5022.27 & 131.84 & 38.09 & $1.32128 \mathrm{E}-38$ & 4757.46 & 5287.08 \\
\hline b & -17960.18 & 800.38 & -22.44 & $9.24282 \mathrm{E}-28$ & -19567.80 & -16352.55 \\
\hline
\end{tabular}

Table 6. Average daily energy $[\mathrm{kWh}]$ generated by the Wicko wind farm in the following weeks of 2019 determined on the basis of real data (Enercon SCADA) and for the linear regression model.

\begin{tabular}{|c|c|c|c|}
\hline Week & $\begin{array}{c}\text { Average daily wind } \\
\text { speed [m/s] } \\
\text { Enercon SCADA }\end{array}$ & $\begin{array}{c}\text { Average daily energy } \\
\text { [kWh] } \\
\text { Enercon SCADA }\end{array}$ & $\begin{array}{c}\text { Average daily energy } \\
\text { [kWh] } \\
\text { Regression model }\end{array}$ \\
\hline (1) & $(2)$ & (3) & (4) \\
\hline 1 & 7.07 & 15906.86 & 17554.45 \\
\hline 2 & 6.66 & 14940.29 & 15473.79 \\
\hline 3 & 5.20 & 7357.86 & 8155.63 \\
\hline 4 & 5.43 & 7486.71 & 9303.58 \\
\hline 5 & 7.17 & 17892.43 & 18056.67 \\
\hline 6 & 6.41 & 13610.00 & 14254.10 \\
\hline 7 & 6.24 & 12996.14 & 13393.14 \\
\hline 8 & 6.19 & 13497.71 & 13106.15 \\
\hline 9 & 9.30 & 25598.43 & 28746.93 \\
\hline 10 & 7.67 & 20186.57 & 20567.81 \\
\hline 11 & 5.91 & 10382.29 & 11742.96 \\
\hline 12 & 6.20 & 14029.43 & 13177.90 \\
\hline 13 & 7.19 & 19536.00 & 18128.42 \\
\hline (1) & (2) & (3) & (4) \\
\hline 14 & 5.17 & 6455.57 & 8012.13 \\
\hline 15 & 4.50 & 5675.29 & 4640.04 \\
\hline 16 & 6.70 & 16180.71 & 15689.03 \\
\hline 17 & 6.31 & 13728.29 & 13751.87 \\
\hline 18 & 5.56 & 10491.00 & 9949.30 \\
\hline 19 & 6.01 & 11237.86 & 12245.19 \\
\hline 20 & 5.10 & 7709.86 & 7653.40 \\
\hline 21 & 4.90 & 6390.86 & 6648.95 \\
\hline 22 & 5.27 & 8969.71 & 8514.36 \\
\hline 23 & 5.33 & 9407.57 & 8801.35 \\
\hline 24 & 4.04 & 3786.71 & 2344.14 \\
\hline 25 & 6.06 & 12364.29 & 12460.43 \\
\hline 26 & 7.79 & 21969.29 & 21141.78 \\
\hline 27 & 4.24 & 4603.00 & 3348.60 \\
\hline 28 & 4.99 & 6480.29 & 7079.43 \\
\hline 29 & 4.67 & 5675.00 & 5501.00 \\
\hline 30 & 3.69 & 2746.00 & 550.48 \\
\hline 31 & 4.90 & 7058.00 & 6648.95 \\
\hline 32 & 4.71 & 5688.00 & 5716.24 \\
\hline 33 & 4.46 & 5329.86 & 4424.80 \\
\hline 34 & 5.77 & 10044.43 & 11025.50 \\
\hline 35 & 4.94 & 6303.29 & 6864.19 \\
\hline 36 & 8.80 & 27346.14 & 26235.80 \\
\hline 37 & 6.04 & 11929.29 & 12388.68 \\
\hline
\end{tabular}




\begin{tabular}{|c|c|c|c|}
\hline 38 & 5.59 & 9132.29 & 10092.79 \\
\hline 39 & 4.19 & 4356.29 & 3061.61 \\
\hline 40 & 6.71 & 15990.14 & 15760.78 \\
\hline 41 & 4.97 & 6767.71 & 7007.68 \\
\hline 42 & 5.99 & 12105.00 & 12101.70 \\
\hline 43 & 4.70 & 5806.14 & 5644.49 \\
\hline 44 & 4.41 & 4466.14 & 4209.56 \\
\hline 45 & 5.61 & 10428.86 & 10236.28 \\
\hline 46 & 6.73 & 15034.14 & 15832.53 \\
\hline 47 & 6.11 & 10325.14 & 12747.42 \\
\hline 48 & 8.03 & 23015.43 & 22361.48 \\
\hline 49 & 7.10 & 16091.00 & 17697.94 \\
\hline 50 & 5.41 & 9383.43 & 9231.83 \\
\hline 51 & 5.87 & 11915.00 & 11527.72 \\
\hline 52 & 10.10 & 37768.00 & 32764.75 \\
\hline
\end{tabular}

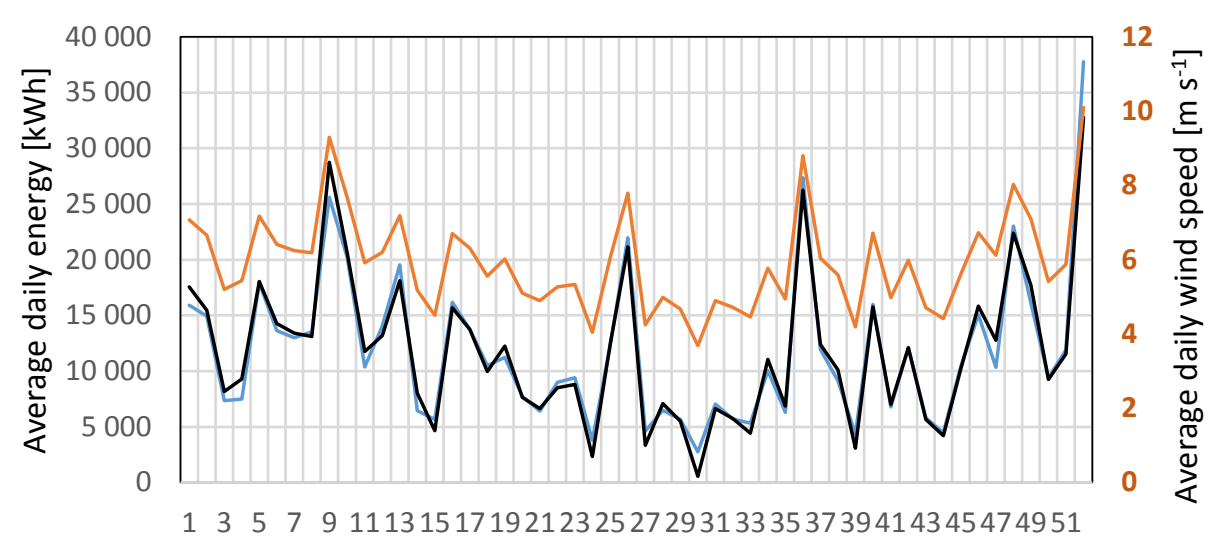

Week

Energy - Enercon SCADA ——Energy - Regression model —Wind speed

Fig. 2. Average monthly energy $[\mathrm{kWh}]$ generated by the Wicko wind farm in the following weeks of 2019 determined on the basis of real data (Enercon SCADA) and for the linear regression model.

\section{Summary}

The research results presented above are the first stage of the work carried out, the aim of which is to develop a predictive method based on solutions in the field of artificial intelligence and expert knowledge. This method will be primarily useful for forecasting the volume of production as well as electricity demand, with particular emphasis on renewable energy sources. The proposed method will be developed with the use of predictive models that enable the analysis of time series (stationary and non-stationary), such as the ARMA and ARIMA models, as well as neural networks. The application of the developed method in practice will facilitate and accelerate the implementation of the decision-making process in electricity production systems, while reducing the risk of making a mistake (making wrong decisions). It is also possible to use the developed models to indicate the benefits of repowering. 


\section{References}

1. B. Parsons, M. M illigan, B. Zavadil, D. B rooks, B. K irby, K. Dragoon, J. Caldwell, Grid impacts of wind power: A summary of recent studies in the United States, in Proc. EWEC, M adrid, Spain, (2003)

2. S. Borowski, M. Szubartowski, L. Knopik, K. Migawa, Wind turbine condition monitoring system as a source of diagnostic information, In Procedings of the 17th International Conference Diagnostics of M achines and V ehicles, (2018)

3. M.I. Blanco, Renew. Sust. Energ. Rev. 13, (2009)

4. G. Szala, B. Ligaj, Fatigue failure and fracture mechanics, p. 69-76, (2012)

5. K. Migawa, L. Knopik, A. Sołtysiak P. Kolber, The method of risk assessment in transport system, Engineering M echanics, (2017)

6. M. Karwowska, J. M ikolajczak, S. B orowski, Z. J. Dolatowski, J. M arc-Pienkowska, W . Budzinski, A nn. A nim. Sci., 14, 441-451, (2014)

7. J. Mikolajczak, S. Borowski, J. Marć-Pienkowska, G. Odrowąż-Sypniewska, Z. B ernacki, J. Siodmiak, P. Szterk, Pol. J. V et. Sci., 16, 679-686, (2013)

8. M. Karwowska, J. Mikolajczak, Z.J. Dolatowski, S. Borowski, Ann. A nim. Sci. 15, 1043-1054, (2015)

9. L. Knopik, K. M igawa, M aintenance and Reliability, 21, 2, (2019)

10. L. Knopik, K. M igawa, A. W dzieczny, Polish M aritime Research, 23, 1, (2016)

11. L. Knopik, K. M igawa, P. Kolber: Statistical analysis of parameters of rail vehicles, Engineering M echanics, (2016)

12. K. Migawa, L. Knopik, A. Neubauer, D. Perczynski, Simulation of the model of technical object availability control, Engineering M echanics, (2017)

13. K. M igawa, L. K nopik, S. Wawrzyniak, A pplication of genetic al gorithm to control the availability of technical systems, Engineering M echanics, (2016) 